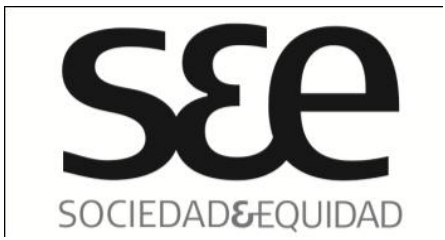

\title{
La metáfora democrática y sus conflictos de interpretación
}

\author{
Nombre: $\quad$ Álvaro Ramis Olivos (*) \\ Universidad: Universidad de Valencia \\ Ciudad: Valencia \\ País: $\quad$ España \\ Correo: alrao@alumni.uv.es
}

\section{Resumen}

Al repasar el debate entre diferentes concepciones normativas de la democracia se constata un conflicto de interpretación sobre los roles del Estado y la sociedad civil, como también sobre la participación ciudadana y la deliberación pública. Los enfoques realistas y normativos han tendido a definir la democracia desde paradigmas descriptivos y procedimentales, lo que parece ser insuficiente para dar cuenta del sentido de las prácticas democráticas. Es necesaria una hermenéutica que refleje el carácter metafórico del proyecto democratico, vinculando los argumentos de la razón con las necesidades de la vida.

\section{Palabras claves}

Democracia, metáfora, deliberación, sociedad civil, hermenéutica.

\section{The democratic metaphor and conflicts of interpretation.}

Reviewing the debate on the different normative concepts of democracy, there proves to be an interpretation conflict on the roles of State and civil society, as well as on civic participation and public deliberation. Realistic and normative approaches have tended to define democracy from the perspective of descriptive and procedural paradigms, which appear to be insufficient in order to disclose the full meaning of democratic practices. It is necessary to develop a hermeneutics of democracy which reflects the metaphorical character of the democratical project, connecting arguments of reason with the necessities of life.

\section{Keywords}

Democracy, metaphor, deliberation, civil society, hermeneutics.

\footnotetext{
(•) El autor es Licenciado en educación. Maestría en Cs. Sociales. Máster en cuestiones contemporáneas de DDHH. Doctorando en Ética y Democracia. Universidad de Valencia. Líneas de investigación: ética de las organizaciones, sociedad civil, democracia deliberativa.
} 


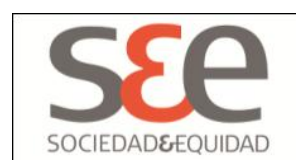

\section{Introducción}

Tras este texto anida una inquietud: la demanda que el movimiento de ciudadanos indignados $15 \mathrm{M}$ ha instalado durante este año en las plazas de España. "Lo llaman democracia y no lo es", se escucha en sus mítines, se lee en sus pancartas, se trasmite por sus redes sociales y encuentra bastante eco en la opinión pública. La afirmación parece indicar que lo que enunciamos como democracia no corresponde con lo que la democracia debería ser. De allí su gran exigencia, "democracia real, ya", dando a entender que el desface entre la democracia existente y la democracia deseada representa una tensión que exige un criterio contrafáctico que permita contrastar nuestra comprensión de lo democrático, y que opere como idea regulativa en este campo. Pero, entonces ¿cual puede ser ese criterio?, ¿cómo distinguir una democracia verdadera, una democracia real, de aquella que llaman democracia pero no lo es? Se trata de un dilema difícil ya que por que por una parte la democracia es algo más que procedimientos, reglas de mayoría y procesos electorales, y por otra sin esos procedimientos, mecanismos y formas de resolución y decisión la democracia pierde su concreción e historicidad. ¿Será posible que la democracia no sólo se pueda describir a partir de modelos argumentativos y descriptivos que operan funcionalmente, en un plano normativo y verificable, sino también desde un plano simbólico, pero que necesita de interpretaciones compartidas?

A partir de este problema el texto asumirá un marco metodológico en el que se explorarán de forma sucinta y apretada diferentes modelos, enfoques o teorías de la democracia, con el afán de llegar a atisbar un posible significado de lo democrático que se sitúe en un campo simbólico que trascienda lo descriptivo y lo prescriptivo y se sitúe en el plano de las interpretaciones del sentido de lo democrático.

\section{¿̇nsatisfacción con la democracia o demócratas insatisfechos?}

¿Que ocurriría si se nos ofreciera estabilidad y un nivel de vida digno, a cambio de abdicar de la democracia? Si bien muchas personas aceptarían gustosas la propuesta, otras estarían dispuestas a hacer grandes sacrificios por vivir y permanecer en democracia. La ambivalencia de este concepto hace que en ciertos contextos huela a corrupción, manipulación y engaño, mientras que en otros sugiera libertad, reconocimiento y progreso.

Una encuesta reciente, aplicada en los países del Este Europeo, sorprendía al revelar que más de un $60 \%$ de los rumanos considera que vivía mejor bajo la dictadura de Nicolae Ceausescu que en la actualidad (TNS CSOP' 2010: 10). Cifras similares se expresaron en los demás países de la región. Se trata de un malestar difuso, que se muestra en apatía electoral, fatalismo, y sobre todo descrédito de las instituciones políticas y sus formalidades electorales. ¿Cambia algo cuando voto? ¿Está siendo tomada en cuenta mi opinión? ¿Tiene peso mi decisión o es sólo un número en la masa? Se trata de preguntas que los gobiernos democráticos no siempre pueden responder con facilidad. 


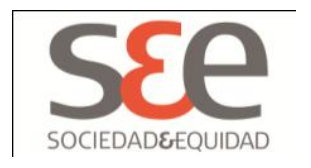

Sin embargo, en otras latitudes la situación es la inversa. Según el estudio de Latinobarómetro "la satisfacción con la democracia alcanza su punto más alto en el año 2009 , con $44 \%$, desde que se empezara a medir en 1995. En el año 2010 se mantiene ese alto porcentaje, confirmando la tendencia en alza sostenida desde 2001 (año de crisis), donde alcanza 25\%" (Latinobarómetro, 2010: 37). Pero el estudio advierte que aunque ha aumentado la legitimidad y adhesión a la democracia persiste un alto porcentaje de "demócratas insatisfechos" que fluctuarían entre el $34 \%$ en 1996 , su punto más alto, y el $15 \%$ en el año 2009 , su punto más bajo. A juicio de Latinobarómetro esta insatisfacción es sana ya que "implica que la democracia está en constante presión por hacer mejorías" (Latinobarómetro, 2010: 34).

Este diagnóstico contradictorio nos muestra que la historia de la democracia es una larga disputa entre quienes buscan delimitar su significado. Una controversia que nace de los diversos modelos conceptuales e ideales normativos que intentan afirmar ese carácter, con mayor o menor exclusividad. Por ello las opiniones respecto a lo democrático pueden ser absolutamente dispares. A modo de ejemplo, el historiador Arthur Rosemberg propuso en 1921 una definición de democracia que parece muy distinta a la que nos hemos acostumbrado: "Democracia es el nombre que recibe el régimen que se instaura como consecuencia de la lucha de clases, cuando las clases explotadas, numéricamente mayoritarias, se constituyen en sujeto político, con proyecto político común, y reclaman el poder para si" (Rosemberg, 2006: 44).

Este conflicto de interpretaciones nos sitúa ante un desafío que el entonces Secretario General de las Naciones Unidas Koffi Annan formuló en Teherán de esta forma: "No existe un solo modelo de democracia, o de los derechos humanos, o de la expresión cultural para todo el mundo. Pero para todo el mundo, tiene que haber democracia, derechos humanos y una libre expresión cultural" (Annan, 1997: 3).

¿Qué horizontes de sentido pueden entonces acercar definiciones tan dispares, si la polisemia democrática refleja a una discusión crucial sobre el ejercicio del poder y su legitimidad en el mundo actual? Se trata de un problema capital, que Giovanni Sartori ha caracterizado muy bien al afirmar: "definir la democracia es importante porque establece qué esperamos de la democracia. Si vamos a definir la democracia de manera "irreal", no encontraremos nunca "realidades democráticas" (Sartori, 2003: 17)

Por este motivo Sartori ha sostenido que toda definición de democracia debe conjugar una función prescriptiva (la democracia deseada) junto a una función descriptiva (que verifique la teoría que hemos prescrito). A mi modo de entender esta distinción nos sitúa entre la democracia empírica y la democracia posible, lo que señala un marco mínimo, pero que no agota las posibilidades de expresar lo democrático. De hecho, la historia nos muestra que las "realidades democráticas" a las que se refiere Sartori exigen de los ciudadanos unas motivaciones que son intangibles, y no por ello menos "reales". Entre la proclamación de un ideal "puro" de democracia y su constatación empírica también opera un lenguaje que se mueve en otro plano, que no pretende señalar modelos concretos ni verificables. Es un lenguaje interpretativo que está más 


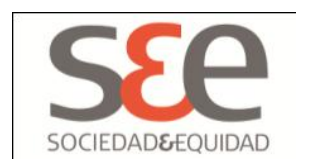

cerca de la poética que de la política, lo que no debería llevarnos a desestimar su valor e influencia en la formulación de los dilemas públicos.

¿Por qué la dimensión heurística y retórica del lenguaje político se ha desvalorizado? La devaluación de este tipo de lenguaje parece correr en paralelo a la reducción del arte a su función expresiva y estética, desvinculando su función epistemológica. Aquellos discursos que no han buscado prescribir modelos, sino inspirar, comprender, abrir a nuevas posibilidades, pero sin la necesidad de operar funcionalmente, en el plano normativo y verificable, han sido relegados y descalificados como inútiles y peligrosos. ¿Tendrá esta situación algo que ver con la desafección democrática de los ciudadanos?

\section{La juridificación de la democracia}

A inicios de los años noventa, Samuel Huntington puso en escena la "tercera ola democratizadora" como una imagen que interpretó el proceso de derrumbe de dictaduras que atravesó al mundo, entre la revolución portuguesa de 1974 hasta la caída de los regímenes comunistas en 1989. Esta fase democratizadora reflejó el fracaso de las dictaduras precedentes, pero también la existencia de nuevos acuerdos y compromisos entre los actores políticos que durante décadas contendieron de forma violenta en el marco de la guerra fría.

Estas nuevas democracias nacieron tensionadas por un temor a la regresión dictatorial y recelosa de las discrepancias ideológicas. Viven así fuertes y justificadas aprehensiones ante posibles recaídas autoritarias y anhelos de estabilidad política que explican el constante interés de los gobiernos de la "tercera ola" por juridificar el concepto de democracia, cerrando la puerta a los fantasmas de la revolución, el golpismo, la ingobernabilidad y la guerra civil. La forma tradicional de alcanzar esta juridificación ha sido la construcción de un modelo de Estado constitucional que tenga como características definitorias los principios del "gobierno representativo" y del "Estado de derecho". Allí radicarían dos postulados básicos y complementarios: la legitimación democrática del poder a través de elecciones periódicas y el "gobierno de las leyes y no de los hombres". Este proceso fue sistematizado por Hans Kelsen a partir de su teoría pura del derecho, la cual en síntesis afirma que "la democracia no es más que un medio de configurar un orden social sobre la base de la voluntad formativa de los propios subordinados a él, y no un específico contenido de este mismo orden social" (Squella, 1984: 3). No cabría por tanto asimilar democracia a un determinado contenido ideológico o económico ya que como afirma Bobbio se trataría solamente de "un conjunto de reglas (primarias o fundamentales) que establecen quién está autorizado para tomar las decisiones colectivas y bajo qué procedimientos" (Bobbio, 1992: 24). Una definición parecida es la de Joseph Schumpeter: "Aquel arreglo institucional para llegar a decisiones políticas; en la cual los individuos adquieren el poder de decidir por medio de una lucha competitiva el voto de la gente" (Schumpeter, 1985: 57). 


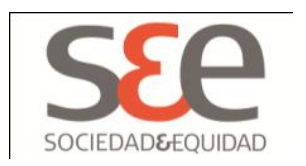

Sin embargo, las experiencias históricas han mostrado la insuficiencia de los marcos constitucionales y legales para garantizar per se la estabilidad de las instituciones democráticas, y por lo tanto vuelven a surgir de forma regular nuevas propuestas de lograr una definición que permita tejer una normativa universal que coaccione de forma activa a quienes pretendan romper la gobernabilidad democrática. Un ejemplo de esta tendencia es la Carta Democrática de la Organización de Estados Americanos, que en su Artículo $3^{\circ}$ propone una delimitación del concepto en estos términos:

Son elementos esenciales de la democracia representativa, entre otros, el respeto a los derechos humanos y las libertades fundamentales; el acceso al poder y su ejercicio con sujeción al estado de derecho; la celebración de elecciones periódicas, libres, justas y basadas en el sufragio universal y secreto como expresión de la soberanía del pueblo; el régimen plural de partidos y organizaciones políticas; y la separación e independencia de los poderes públicos.

(OEA, 2001: 9)

Este tipo de "cláusulas democráticas" comienzan a proliferar en diversos tratados internacionales, tales como los acuerdos de asociación de la Unión Europea con terceros países, estableciendo medidas específicas con el objeto de hacer inviable la consolidación de un régimen de facto. Aunque se acepta la conveniencia de estas normas como un recurso disuasorio, su formulación no está exenta de críticas. En parte por su eficacia limitada, y también por la inflación legislativa que conllevan. Pero las observaciones más críticas se realizan en relación a su contenido. Se argumenta que se pretende clausurar la democracia en un concepto jurídico, olvidando que se trata de una construcción social inacabada y por lo tanto, objeto de desarrollos y debates permanentes. Se caería así en un reduccionismo legalista que vaciaría a la democracia como proyecto de autodeterminación colectiva. Se ve en este empeño una propuesta que identificaría la democracia con los procesos de elección y gobierno a los que se ha logrado arribar de forma histórica, instaurándolos como un orden incuestionable e inmutable, que desincentivarían la innovación política. Cabe recordar las observaciones que Aranguren hacía respecto a las distinciones de la democracia como status o como conquista:

La democracia no es un status en el que pueda un pueblo cómodamente instalarse. Es una conquista ético-política de cada día, que sólo a través de una autocrítica siempre vigilante puede mantenerse. Es más una aspiración que una posesión. Es como decía Kant de la 


\section{SEe}

moral en general, una "tarea infinita" en la que si no se progresa se retrocede, pues incluso lo ya ganado ha de reconquistarse cada día.

(López Aranguren, 2011: 128)

\section{Democracia y poliarquía}

Los críticos del procedimentalismo de Kelsen o Schumpeter sostienen que esa concepción de la democracia deriva en un funcionamiento rígidamente "agregativo", basado en el principio de sumar intereses individuales hasta formar una mayoría. En este proceso el "cómo" se alcanza esa mayoría no sería relevante. Lo importante sería resolver, decidir, elegir. Pero para llegar a hacerlo se podría recurrir a muchos recursos: a la manipulación de las emociones y las conciencias, al engaño más o menos flagrante, a la presión de los más ricos o de los más fuertes, a la traición a los ideales declarados y a las promesas formuladas. No importaría, porque las elecciones se ganan con votos y nada más que con votos. Se trata de un enorme paso civilizador, que nos ha permitido superar la violencia como mecanismo de resolución política, pero claramente insuficiente.

Autores como Robert A. Dahl (1992) han complejizado las definiciones anteriores al afirmar que la democracia "realmente existente" sería un régimen poliárquico, es decir, una conexión entre múltiples grupos e instituciones que interactúan entre sí, y no sólo un proceso electoral. Para Dahl existiría una serie de requisitos mínimos que caracterizarían a este tipo de gobierno: funcionarios electos, elecciones libres e imparciales, sufragio inclusivo, derecho a ocupar cargos públicos, libertad de expresión, variedad de fuentes de información y autonomía asociativa. En consecuencia, si estos criterios se han positivado legalmente estaríamos ante un régimen que podría aspirar a denominarse democrático, aunque reconoce que ningún orden político actual cumple suficientemente estos predicamentos. De esta forma el ideal democrático sería en último término un objetivo inalcanzable (Dahl, 1992).

\section{Democracia y economía: exigencias recíprocas}

En otro ángulo del debate, y desde otras escuelas, se ha rechazado la neutralidad axiológica que arranca del positivismo jurídico de Kelsen, tratando de afirmar relaciones de causalidad necesaria entre un determinado modelo económico y la democracia. Desde la perspectiva neoliberal, Michael Mandelbaum (2008) sostiene que:

La fuente principal de la democracia política es la economía de libre mercado. Si bien es cierto que ha habido y continúa habiendo países que practican la economía del libre mercado pero no la democracia política, ningún país en el siglo XXI que se considere una democracia política carece de una economía de libre mercado.

(Mandelbaum, 2008) 


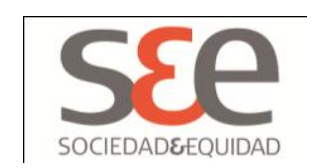

En respuesta a Mandelbaum el ex secretario de trabajo de Estados Unidos Robert Reich ha señalado que:

Democracia significa mucho más que un proceso de elecciones libres y justas. Es un sistema para lograr lo que sólo puede lograrse cuando los ciudadanos se juntan para conseguir el bien común. Pero aunque el mercado libre trajo prosperidad sin precedentes a muchos, vino acompañado por profundización de desigualdades de ingreso y riqueza, aumento de inseguridad en el empleo y peligros ambientales como el calentamiento global.... la democracia no puede cumplir con su función cuando las empresas usan la política para mejorar o mantener su posición competitiva, o cuando parecen adoptar responsabilidades sociales que en realidad no tienen ni capacidad ni autoridad para asumir.

(Reich, 2007: 23)

Por este motivo la relación entre democracia y modelos económicos debería entender se como una serie de demandas éticas interconectadas. La democracia plantea exigencias a la economía y a su vez la economía plantea desafíos a la democracia. Esta última perspectiva la ha puesto en evidencia el Informe regional sobre desarrollo humano para América Latina y el Caribe 2010. En esa investigación se identifica una serie de mecanismos propios de la cultura política latinoamericana que refuerzan la reproducción de la desigualdad, impactando en especial en las mujeres y la población indígena y afrodescendiente. Entre estos factores destaca la baja estabilidad y credibilidad de las instituciones estatales, la discrecionalidad del ejercicio del poder público, la escasa deliberación política, el desigual acceso a las redes de influencia, y las fallas institucionales que derivan en prácticas de corrupción, clientelismo y captura del Estado. Estas circunstancias imposibilitan a la democracia contrarrestar las desigualdades, debido a que los actores políticos responden de manera sesgada y discriminatoria a las necesidades de quienes se han visto históricamente excluidos.

\section{Democracia e interculturalidad}

Otros autores han argumentado una supuesta incompatibilidad absoluta de algunas culturas con la democracia. La más recurrente es la llamada "excepción árabe". Amos Perlmutter, columnista del Washington Post, se preguntaba en 1997: "El Islam, sea integrista o no, ¿es compatible con la democracia representativa de tipo occidental, orientada hacia los derechos del hombre y liberal? La respuesta es claramente no" (Perlmutter, 1997). 


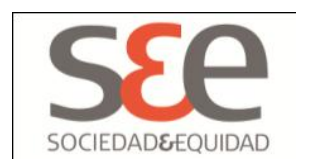

Pero las recientes manifestaciones democráticas de Túnez y Egipto parecen contradecir este determinismo histórico. Como ha comentado Slavoj Žižek (2011), "La sabiduría cínica de liberales occidentales, según la cual, en países árabes, el verdadero sentido democrático se limita a estrechas elites liberales mientras la vasta mayoría sólo puede ser movilizada por el fundamentalismo religioso o el nacionalismo, ha resultado ser errónea".

Al respecto, Amartya Sen (2006) ha hecho ver las inconsistencias históricas de las tesis que sostienen la excepcionalidad occidental de la democracia. En su argumento Sen propone que la democracia se debe entender más allá de sus instituciones actuales, y que lo nuclear de ella descansa en la deliberación pública. Desde esa perspectiva la democracia no constituiría una experiencia histórica exclusiva de Europa occidental ya que también habría sido desarrollada en otros contextos, entre ellos, en India, China, Japón, Corea, Irán, Turquía, los pueblos árabes y africanos, y podríamos agregar, los pueblos indígenas y aborígenes tanto en América como en otras latitudes. La argumentación de Sen nos permite descubrir que si bien Grecia hace un aporte específico a la teoría de la democracia, no fue la única cultura que desarrolló prácticas colectivas de discusión y resolución, basadas en el diálogo y la argumentación por lo cual se hace insostenible la supuesta originalidad democrática de occidente.

A pesar de lo anterior no es menos cierto que los contextos sociales y culturales no son irrelevantes a la hora de implementar un determinado modelo de Estado. Se trata del tipo de factores a los que se refería René Zavaleta al estudiar Bolivia como "sociedad abigarrada" y que le llevaban a preguntarse: “¿Cómo podría, por ejemplo, un pueblo como el peruano o el boliviano llegar a su autodeterminación sin considerar que la servidumbre está en medio de la tradición popular?" (Zavaleta, 2009: 187). De la misma forma la filósofa bengalí Gayatri Spivak en su famoso ensayo "¿Pueden hablar los subalternos?” cuestionó radicalmente el significado de las representaciones para quienes, si bien físicamente pueden hablar, no gozan de una posibilidad de expresarse y ser escuchados, aquellos sujetos que por su estatus social carecen de "agencia" y de voz. En opinión de Spivak los "subalternos" señalarían un límite a la representación democrática como aquellos que no pueden ser representados: ni hablan ni podemos hablar por ellos.

\section{Democracia como deliberación}

En este amplio campo de debates cruzados y abiertos muestra la necesidad de aportar nuevos conceptos de democracia, más aún si constatamos que los problemas fundamentales siguen en curso. En ese contexto se inscribe el llamado "giro deliberativo" que ha abierto un nuevo debate sobre la definición de democracia. Se trata de una propuesta que acentúa el proceso de deliberación pública como momento central y coloca a la elección en un plano subordinado. En esa resolución final cabría o no la posibilidad de votar, pero en caso alguno se plantea equiparar democracia a elecciones. Democracia es, en este sentido, la puesta en práctica de la autonomía crítica de los ciudadanos. El valor de la deliberación democrática no sería sólo circunstancial, sino un fin en sí. 


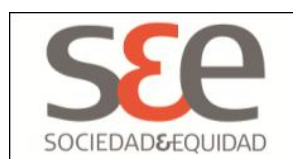

Se suele descalificar la propuesta deliberativa afirmando que cae en las limitaciones propias de la democracia directa o "congregativa", que no es viable sino en comunidades muy reducidas. Por este motivo quienes proponen la idea de democracia deliberativa buscan fundamentar su propuesta en elementos que vayan más allá de las fronteras de la democracia directa, recogiendo como elemento esencial en la tradición democrática la formación de un juicio propio por parte de los afectados en las deliberaciones.

Jürgen Habermas ha sugerido un concepto procedimental de democracia que cuente con "la intersubjetividad de orden superior que representan los procesos de entendimiento que se efectúan a través de los procedimientos democráticos o en la red de los espacios públicos políticos" (Habermas, 2008: 376). Bajo esta lógica, y respetando los límites entre Estado y sociedad Civil, se propone que la opinión pública, transformada mediante procedimientos democráticos en poder comunicativo, racionalice las decisiones de la administración y el gobierno, orientándolas en una determinada dirección, sin por ello asumir el poder estatal. Para ello es necesario garantizar institucionalmente diversos espacios públicos autónomos y procedimientos de formación democrática de la opinión y la voluntad, que se puedan sostener autónomamente frente al poder del sistema económico y al poder de la administración pública.

Estos planteamientos poseen enormes consecuencias, en múltiples áreas. Sólo a modo de ejemplo, en el debate sobre el rol del tercer sector en las comunicaciones o en la creciente visibilización de experiencias deliberativas. En esa perspectiva Boaventura de Sousa Santos ha propuesto en contrapartida a las definiciones jurídicas el concepto de demodiversidad, con el fin de demandar el reconocimiento de diferentes modelos y prácticas democráticas que van más allá de la democracia representativa, como las prácticas de deliberación comunitaria en comunidades indígenas, la participación ciudadana en la evaluación de impactos científicos y tecnológicos, los panchayats - consejos de aldea - elegidos en Kerala y Bengala Occidental y las nuevas prácticas de participación a través de la democracia electrónica (De Souza Santos, 2004).

Adela Cortina ha destacado los enormes recursos prácticos y epistémicos que supone la democracia deliberativa. El diálogo produce conocimiento, incorpora los saberes y pareceres de la población, ofrece más alternativas de gestión eficiente de los asuntos públicos, adecua de forma más completa los intereses de las mayorías y los de las minorías. Porque tal como reflexionaba Dewey, para Cortina lo más importante no es saber quienes son mayoría, sino cómo esa mayoría ha llegado a serlo. ¿Lo han hecho por su capacidad de convencimiento o por la fuerza del dinero, de las armas o de la mentira? Si a una masa es posible moverla por emoción, a un pueblo sólo se le convoca si tiene puntos comunes a los que llegar por convicción. Por este motivo la democracia deliberativa es altamente legitimante, ya que las personas que han participado, aunque no se sientan totalmente satisfechas del resultado final, experimentan que se les ha reconocido en el proceso argumentativo y decisional (Cortina, 2010). 


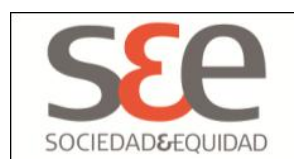

Es obvio que los procesos de deliberación ciudadana otorgan viabilidad y credibilidad a las políticas públicas, reforzando la confianza en las autoridades e instituciones. Sin embargo, a pesar de todos estos argumentos, los políticos siguen rehuyendo la participación ciudadana efectiva, bajo argumentos de eficacia y eficiencia, lo que revela una grave ignorancia y una fuerte inseguridad. Porque lo que se aspira no es a una participación declarativa o decorativa, ya que como afirma Amartya Sen la democracia deliberativa "incluye la oportunidad de los ciudadanos de participar en la discusión política y de encontrarse en la posición de influenciar la elección publica" (Sen, 2006: 3)

En el terreno práctico, Adela Cortina (2010) propone, desde los planteamientos de Henry S. Richardson, que todo proceso deliberativo debería tener al menos cuatro etapas:

1. Un momento en el que los interlocutores expongan los términos del desacuerdo desde su punto de vista, tanto en relación a las metas como a los medios para alcanzarlas.

2. Un tiempo para argumentar las propuestas, bajo la condición de ofrecer reciprocidad. Es decir, se deben dar razones capaces de ser entendidas y aceptadas por los demás. La aceptabilidad de las propuestas supone un mínimo deber de civilidad y empatía que impida los argumentos tautológicos o las imposiciones apriorísticas.

3. En tercer lugar es necesario llegar a un acuerdo informado pero informal. Ese es el momento en que cabe a cada parte para responsabilizarse de lo que le atañe en la decisión a adoptar. Es un momento de interiorización y profundización de lo sancionado y su revisión hasta la saciedad.

4. En último lugar, el acuerdo final y formal. En ese momento puede caber una votación, pero como ya se ha descrito, se trata de una votación distinta a la que normalmente enfrentamos cotidianamente.

Todo este proceso exige que se opere bajo el llamado "principio de publicidad", con absoluta transparencia y acceso público a la información relevante y pertinente a la deliberación. Además es requisito que las decisiones no sean irreversibles, sino revisables, corregibles y en permanente adecuación. Tras esta tradición se reconoce, con pensadores como Aristóteles, que en una sociedad siempre habrá muchas ideas del bien y la felicidad. Visiones diferentes sobre lo que puede ser la "vida buena". Es preciso reconocer esta pluralidad y rechazar la pretensión de quienes tratan de imponer como leyes naturales, permanentes y eternas sus propias preferencias. El problema ante esta diversidad es dirimir cómo convivir en justicia. ¿Que espacios permiten una deliberación que garantice los derechos fundamentales de todos y no impidan a nadie buscar la felicidad que anhela? Preguntas que exigen dar hondura dialógica a la democracia, sobre la base de la escucha a un diferente, reconocido como legítimo. Y como diría Habermas, concediendo competencia comunicativa a los ciudadanos. 


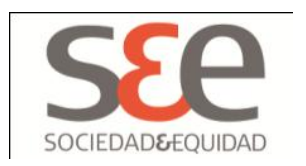

\section{Democracia agonística: ¿los límites de la deliberación?}

Chantal Mouffe ha desarrollado observaciones críticas ante la democracia deliberativa, especialmente en "La paradoja democrática" (Mouffe, 2003), donde sostiene que el conflicto y el pluralismo serían elementos específicos de la democracia ya que el antagonismo es inherente a "lo político". Esta dimensión lejos de ser mitigada debería ser considerada un "principio axiológico". En respuesta a esta realidad surgiría "la política", entendida como las prácticas e instituciones que buscan establecer un orden que permita la coexistencia, pero siempre en condiciones potencialmente conflictivas.

Por este motivo Mouffe niega que la democracia se pueda concebir como una deliberación permanente por medio de la cual se puedan lograr acuerdos y resultados que satisfagan a todas las partes, ya que ello significaría negar las relaciones de poder y las asimetrías económicas y culturales que delimitan el campo de lo político. Además, el consensualismo democrático llevaría a diluir las diferencias programáticas, identificando la alternancia con la existencia de alternativas. A su juicio el consensualismo abriría campo a fuerzas no democráticas, específicamente a los partidos populistas de derecha, que ocuparían el espacio de la disidencia social con discursos racistas y discriminadores. Por ello propone alcanzar un modelo agonístico en el cual las diferencias políticas se puedan resolver en relaciones propias de adversarios legítimos y no de enemigos.

El planteamiento de Mouffe, a mi entender, identifica erróneamente las propuestas de la democracia deliberativa con los programas políticos propios de la llamada "tercera vía" y las políticas de consenso que se han establecido para implementar "pactos sociales" generalmente entre los gobiernos y entidades representativas como los sindicatos y las confederaciones patronales. Tal como la ética del discurso han sostenido al responder al problema de la situación o comunidad ideal de habla, este contexto deliberativo se debe entender como un principio regulativo contrafáctico que no niega la existencia de las asimetrías y desigualdades que se pueden constatar en cada contexto discursivo. Creo que las advertencias de Mouffe pueden ser tenidas en cuenta como interpelaciones necesarias para complejizar el debate sobre la democracia deliberativa pero no constituyen argumentos que clausuren la necesidad de explorar la dimensión deliberativa de la democracia.

\section{Democracia "monitorizada", contrademocracia, lobbycracia y posdemocracia}

El debate más reciente sobre la democracia también exige dar cuenta de conceptos emergentes, tales como la "contrademocracia" (Rosanvallon, 2007) y las ideas sobre una "democracia monitorizada" (Keane, 2009). Ambas propuestas se enmarcan en la posibilidad de ampliar los controles que la sociedad civil puede ejercer respecto a los gobiernos, gracias a las nuevas tecnologías de la información y al fortalecimiento del rol de la sociedad civil organizada. Se trata, según Rosanvallon, del conjunto de las intervenciones ciudadanas frente a los poderes que operan como ejercicios democráticos no institucionalizados, reactivos, que expresan de forma directa las expectativas y decepciones ciudadanas. La posición de Keane es parecida ya que 


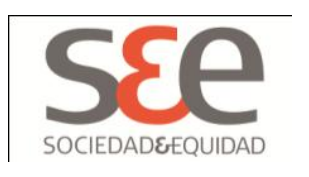

destaca la creciente importancia de mecanismos e instrumentos de vigilancia que la sociedad civil puede desplegar para monitorizar al poder. Un ejemplo actual de estos procesos lo constituye, a mi juicio, la acción Wikilieaks y otras plataformas similares. Pero más allá de la publicidad de estos casos, se pueden identificar una serie de observatorios ciudadanos que monitorean políticas públicas y debates ligados a derechos humanos que han adquirido competencias importantes, y que poseen innegable capacidad de incidencia política.

Recientemente el constitucionalista José María Ruiz Soroa (2009) ha profundizado en estas ideas desde una perspectiva jurídico-institucional en "Esencialismo democrático", obra a la que sólo se ha tenido acceso superficial en el momento de redactar este artículo:

Se trata de superar el juego de suma cero a que conduce la oposición binaria entre democracia y constitución, entre pueblo y juez constitucional. Lo cual exige replantear críticamente el mito de la democracia directa e instantánea protagonizada por el pueblo, poniendo en su lugar la soberanía multipolar de unas instituciones que interactúan y se controlan mutuamente a lo largo de tiempos distintos. El sistema democrático es una especie de cámara de espejos que se reflejan y controlan unos a otros, y el pueblo no es sino la atmósfera que habita entre ellos.

(Ruiz Soroa, 2009)

Simultáneamente, junto a esta tendencia que expresa un fortalecimiento de la Sociedad Civil y el despliegue de las potencialidades institucionales de un Estado social de derecho, también se debe constatar el rol antidemocrático que juegan los grupos de presión ligados a poderosos sectores corporativos, que han llevado a la creación del neologismo "lobbycracia", que connota la influencia que ejercen los llamados "policy makers" en espacios de decisión tales como Washington o Bruselas. En la misma línea el sociólogo Colin Crouch (2004) ha alertado bajo el concepto de "posdemocracia" respecto a un posible estadio de decadencia y retroceso predemocrático de las democracias avanzadas, luego de haber llegado a un límite en la expansión de los derechos y libertades ciudadanas. Se trataría de una involución política que tendría como síntomas la banalización y corrupción endémica de los partidos políticos y los procesos electorales. 


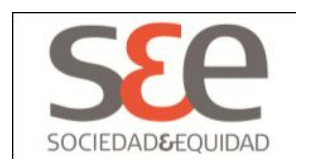

\section{La metáfora democrática}

Las diversas experiencias y conceptualizaciones que hemos revisado muestran el grado de indeterminación que atañe a la definición de democracia. Se trata de un debate casi irresoluble que obliga a buscar condiciones de validez que eviten conceder el atributo democrático a procesos contradictorios. ¿Pero cómo evitar que el discernimiento de las prácticas democráticas quede librado a pautas dispares que anticiparían un irracionalismo permanente en los juicios políticos? Consideremos que la opinión pública transita normalmente en medio de discursos emotivistas y esencialistas que califican a la democracia como un engaño (el "imperio de los mediocres" de Nietzsche) o un proyecto de vida tan exigente que sólo una minoría muy convencida y formada podría vivirlo (una conclusión que se podría llegar a extraer de propuestas como la "democracia fuerte" planteada por Benjamin Barber).

Las delimitaciones conceptuales que aportan autores como Giovanni Sartori y Robert Dahl dan pie a criterios básicos que sin duda son fundamentales. Sin embargo, sus definiciones de democracia se mueven en un comprensible afán descriptivo y prescriptivo, que teme del "idealismo" y "perfeccionismo" democráticos y por lo tanto terminan apostando por un concepto realista y empirista. Lo que esa perspectiva asegura es marco democrático funcional, operativo, pero no logra dar cuenta del sentido profundo de esas prácticas. ¿Basta ese realismo político para interpretar las expectativas de la ciudadanía? ¿No se requerirá además un tipo de lenguaje que de cuenta de los factores que hacen preferible y deseable la vida democrática a otras formas funcionales y operativas de gobierno?

Esta aporía hace necesario devolver a la democracia su lugar en el ámbito del lenguaje heurístico, como una metáfora vigorosa que se ha construido de modo progresivo y que posee un carácter polisémico, aunque no irracional ni arbitrario. Esto no implica una clausura conceptual, sino la posibilidad de la interpretación en un plano distinto y complementario a las teorías realistas y normativas vigentes. Este acercamiento aporta elementos a la hora de resolver la complejidad de la realidad democrática, permitiendo que los ciudadanos sintonicen a nivel experiencial y no sólo a partir de argumentos racionales.

\section{Lincoln y el gobierno del pueblo}

Históricamente podríamos identificar una serie de proposiciones que han apuntado a interpretar la democracia por medio de metáforas, más o menos afortunadas. Una de las más famosas, y que sirve para ejemplificar este recueso metáforico, es la que formuló Abraham Lincoln en la célebre "Oración fúnebre de Gettysburg" en 1863. Vale la pena señalar que esta frase cierra un breve discurso de no más de 300 palabras, que para varios autores posee claras influencias de la llamada "oración fúnebre de Pericles". El discurso de Lincoln ha logrado resonancias a múltiples niveles. Se trata de una metáfora evocadora que contiene todo un programa político: "El gobierno del pueblo, para el pueblo y por el pueblo". Una formulación cuya paráfrasis es infinita e inagotable, y cuyo valor recae en la tensión entre todos los términos que constituyen el enunciado. 


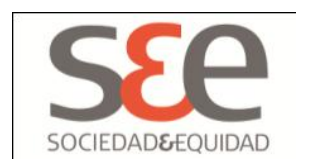

El discurso se sitúa en un contexto de crisis política, en la que la conducción de la guerra civil por parte de Lincoln es cuestionada abiertamente por sus adversarios, que están dispuestos a dar concesiones al Sur confederado con tal de finalizar la contienda, que ya había causado cientos de miles de muertos. Por este motivo la intervención de Lincoln apunta a dar un significado a ese esfuerzo. En ocasión de la inauguración de un cementerio militar en Gettysburg el presidente retrotrae la memoria a los orígenes de la nación y sitúa la actual contienda como una prueba a sus valores fundacionales. Entre ellos, el que comprende como el más original y propio como es el gobierno democrático, una auténtica excepción en un contexto en el que aún eran escasas esas experiencias. La frase clave que cierra la intervención ("and that government of the people, by the people, for the people, shall not perish from the earth") pone el punto de tensión fundamental. Para Lincoln lo que está en juego en esa guerra es la supervivencia de la democracia. Pero la democracia entendida de una forma específicamente integral, que no puede ser expresada de una forma trivial. La historiografía estadounidense han establecido que Lincoln recogió esta expresión de un sermón del pastor Theodore Parker, un líder abolicionista de gran fama en este momento, quién se habría inspirado a su vez en el prólogo a la Biblia traducida al Ingles por el reformador John Wycliffe en el siglo XII. La frase textual de Parker era: "Democracy is direct selfgovernment, over all the people, for all the people, by all the people".

\section{Objeciones de Giovanni Sartori}

Vale la pena detenerse en los comentarios que Sartori (2003) realiza sobre la afirmación de Lincoln ya que sirven para ilustrar la forma como se ha tendido a leer este tipo de lenguaje político. Sartori analiza esta frase en el contexto del estudio de lo que llama "democracia etimológica" o "literal", en referencia al afán de hacer que la democracia sea lo que dice la palabra: sistemas y regímenes en los que el pueblo manda. Ya hemos detallado que para Sartori las definiciones de democracia pueden ser prescriptivas o descriptivas. De acuerdo a estos criterios todo acercamiento a la democracia desde su origen etimológico nos llevará a un callejón sin salida, ya que no sabemos que entender por "pueblo" y menos como operativizar el "poder" de ese pueblo.

Si hablamos de "pueblo" la polisemia de sentidos nos puede llevar a cosas distintas: pueblo como todos, pueblo como los más, pueblo como populacho o clases populares, pueblo como totalidad orgánica, pueblo como mayoría absoluta o pueblo como mayoría moderada. En Inglés, "people" (literalmente personas) entraña un a connotación diferente a "pueblo", ya que en el primer caso apunta a una multiplicidad, un agregado de individualidades. En cambio la expresión castellana se tiende a comprender como una totalidad orgánica. Por este motivo la expresión de Lincoln llevaría a confusiones.

Para Sartori, si quisiéramos dar pie a la expresión "gobierno del pueblo" en el actual contexto social podríamos caer en la "masacracia", en el poder de las masas, fenómenos que muy bien denunció Ortega y Gasset. Por este motivo el autor concluye que "una democracia entendida a la letra sólo puede ser una sociedad sin Estado y se entiende, sin sustitutos o equivalentes del 


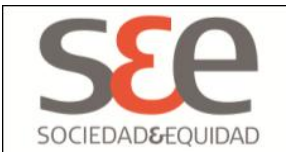

Estado" (Sartori, 2003: 42). Por lo tanto, la expresión de Lincoln caería en una insuficiencia y en una contradicción fundamental.

Respecto al gobierno "para el pueblo" se objeta que aunque está claro que es en beneficio del pueblo, es una expresión que puede usar el tirano: "Pongámoslo hipotéticamente en boca de Stalin. ¿Hipótesis absurda? No, Stalin no hubiera tenido dificultad de firmarlo, entendiendo el gobierno del pueblo en el sentido de que el proletariado era el objeto de su gobierno y que el gobernaba mediante el pueblo en el interés del proletariado, para el pueblo" (Sartori, 2003: 44). Por estas razones Sartori afirma que el aforismo de Lincoln no es preciso y no concluye, por lo cual es necesario descartar este acercamiento y entrar de lleno en un enfoque realista del proceso democrático.

\section{Gettysburg como metáfora}

El análisis de Sartori es justo si se asume que el aforismo de Lincoln sólo admite una literalidad unívocamente descriptiva o prescriptiva. Si es así deberíamos concordar en que las referencias al gobierno "del, para y por el pueblo" reflejan muy poco de los procesos políticos reales y es imposible aplicar su contenido. Sin embargo, también podemos entender que Lincoln desea transportarnos al sentido de las prácticas democráticas, colocando ante nuestros ojos lo que ellas podrían ser, aunque inevitablemente no lo logren. Se trataría entonces de una descripción especulativa con el fin de persuadir. Una metáfora que logra percibir bien las semejanzas entre los diferentes conceptos que constituyen su aforismo. Semejanzas, ni equivalencias o causalidades necesarias.

Al respecto la metáfora constituye una predicación "impertinente", en cuanto rompe con las referencias habituales de los términos que la componen, generando así una nueva referencia, pero también un nuevo sentido, diferente al literal. Paul Ricoeur ha explicado este proceso de resignificación distinguiendo entre referencias descriptivas y referencias metafóricas. Esta última no tiene la intención de mostrar, prescribir o describir el mundo sino re-crearlo, ampliando la comprensión del sentido de la afirmación. Esta forma de referencia sería la propia de la ficción y la poesía. La metáfora viva sería aquella que es capaz de activar la imaginación, haciendo pensar sobre lo que se dice de un determinado concepto, superando y ampliando el significado convencional del mismo, ya que operaría a dos niveles de significación simultáneamente, tal como lo hacen los símbolos (Ricoeur, 1977).

Lo que hace Lincoln es una trasposición sorprendente, inesperada, designando un modo de gobierno de un modo extraño. En este caso, lo corriente, lo normal sería afirmar el gobierno de alguien, de un individuo, el gobierno de alguna persona sobre el pueblo. El gobierno "del presidente $x$ " o "del partido z.", pero decir, el gobierno "del, para y por el pueblo" es de partida una desviación que va contra el uso corriente, y una "epífora" o reiteración retórica que acentúa la extrañeza del enunciado. Sin embargo no se trata de una expresión oscura, elaborada con palabras extrañas o rebuscadas. Se trata de una expresión clara, cálida, en buen tono, conveniente y que ha sabido escoger los elementos apropiados para su formulación. Se trata de 


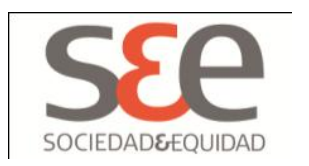

una buena metáfora, que pone en acción un concepto inanimado como es el gobierno, de mano del pueblo que ejerce el poder.

De esta forma "del, para y por el pueblo" opera de forma interpretativa más que descriptiva, al dar pie a lo que la democracia debería buscar tanto en sus fundamentos como en sus procedimientos. Recurriendo a un lenguaje más poético que jurídico Lincoln ha develado intuitivamente el corazón del anhelo democrático, pero de una manera en que su significado debe adivinarse sin que se logre una estabilidad definitiva en su significado final. Más aún, nos muestra lo que en esa búsqueda inacabada la democracia ya está desarrollando su sentido. La proposición de Lincoln no es una utopía irrealizable y peligrosa como sugiere la lectura de Sartori, sino una descripción que amplía nuestro conocimiento de lo que entraña el proyecto democrático.

Pero no se trata sólo de una analogía o una comparación. En "el gobierno del pueblo, para el pueblo y por el pueblo" opera lo que I. R. Richardson ha denominado la interanimación de las palabras que componen esta oración. El sentido literal de la afirmación interactúa con su sentido metafórico y produce un efecto novedoso y extraño en una audiencia universal que debe validar el sentido de este mensaje. En cierta forma, la metáfora de Lincoln opera como un criterio contrafáctico con el cual contrastar las experiencias democráticas.

Ronald Dworking (2003) ha reinterpretado las tres preposiciones de la metáfora de Gettysburg al proponer una concepción asociativa de la democracia basada en tres dimensiones: soberanía popular (como exigencia que el pueblo -y no los funcionarios- gobiernen), igualdad de los ciudadanos (permitiendo que los ciudadanos sean iguales no sólo como jueces del proceso político, sino también como participantes en él) y discurso democrático (si el pueblo va a gobernarse colectivamente, de una manera que haga a todos y cada uno de los ciudadanos socios en la empresa política, entonces éstos deben deliberar juntos como individuos antes de actuar colectivamente,) (Dworking, 2003: 395-396). Tres principios que profundizan la concepción lincolniana, pero que no agotan su fuerza evocadora y su capacidad creativa.

\section{Riesgos y límites de la metáfora política}

El peligro de la metáfora en el lenguaje político radica en que la búsqueda del sentido haga olvidar la referencia, que tiene relación con la coherencia y la verificación de lo que se expresa. La metáfora entraña un riesgo inevitable de equivocidad, ya que en un afán de "mostrar" puede terminar por no "decir" nada. Por este motivo demandaría de una hermenéutica crítica que proporcione criterios universalizables que delimiten la inevitable inconmensurabilidad de lo metafórizado. Para que la metáfora de Lincoln cumpla su función heurística debería pasar por criterios de autenticidad, que exijan un contexto dialógico de interpretación en el que no sería indiferente quién la pronuncia, y cuando la utiliza. 


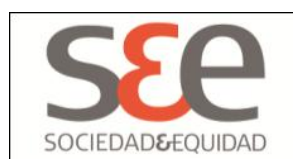

Usando la expresión de Ricoeur pueden encontrarse metáforas vivas, metáforas desgastadas y metáforas definitivamente muertas, que conviven en los discursos contemporáneos. Así entendemos que otras metáforas políticas, como la "representación ciudadana" o el "contrato social" parezcan hoy desgastadas y produzcan resistencia en las audiencias. Y claramente otras metáforas como "democracia popular", "democracia orgánica" o "centralismo democrático" sean hoy imágenes muertas que ya nada dicen ni nadie quiere resucitar. Por lo tanto entender la democracia desde la metáfora no puede ser un proyecto arbitrario ya que supondría una comunidad de sentido y horizontes de interpretación que den vida a la imagen que se propone.

\section{Conclusión: razones y sentidos de la democracia}

Al comenzar el texto nos referimos a las demandas del movimiento ciudadano $15 \mathrm{M}$ por una democracia real. Lejos de llegar a una definición que permita dar respuesta a esta intepelación, el texto ha tratado de mostrar las dificultades de llegar a definiciones unívocas de la democracia. Como alternativa se propone situarla en el ámbito de las metáforas, lo que impide la clausura de su significado y por otra la constriñe a un marco intersubjetivo de interpretación. En otras palabras, el somero recorrido por los modelos de democracia que se han descrito mostrarían que no es posible ni deseable ofrecer una definición definitiva de la democracia sin caer en la contradicción performativa de pretender cerrar un debate que demanda por su carácter una apertura creativa. Por otro lado, al pensar la democracia como metáfora permitimos que opere un juicio sobre la pertinencia democrática de ciertas afirmaciones o de ciertos procesos políticos. La función metafórica opera así como una mediación crítica interpretativa de los procesos democráticos, un espacio que no se sitúa propiamente ni en la discusividad poética pero tampoco en la operatividad política funcional. Se valoriza así la dimensión heurística y retórica del lenguaje político, que se han desvalorizado en forma paralela a la reducción del arte a su función expresiva y estética, desvinculándole de su función epistemológica.

Al sostener esta idea no se quiere cerrar la puerta a las definiciones formales de democracia. Sólo busca dar espacio a un requerimiento social que aspira a algo más que la trivial contemplación de los ejercicios electorales. Ya en los años sesenta José Luis López Aranguren advertía sobre las pretensiones de un tipo racionalismo político que parte de una idea sin más y exige que la realidad se acomode a ella.

El filósofo moral va perdiendo el interés en los temas políticos en la medida en que estos temas se van acercando a la realidad. Lo que a él le importa es la tesis no la hipótesis...Que esa tesis sea irrealizable o muy difícil de realizar es cuestión que a él le afecta muy poco. Tal imposibilidad o suma dificultad se encuentra en un plano, el de la realidad, que importa ciertamente al político pero del que el filósofo absorto en el arquetipo y la idea se desentiende tranquilamente". Superar esta distancia entre teoría y 


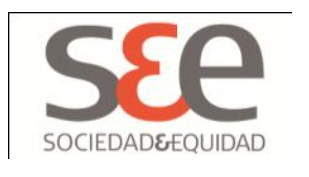

práctica justifica la búsqueda de una hermenéutica de la vida cívica, que acompañe al desarrollo de las propuestas normativas de la democracia.

(López Aranguren, 2001: 23)

Adela Cortina (2009) ha profundizado en este aspecto cuando ha afirmado que:

El éxito de una acción comunicativa exige que los interlocutores no se reconozcan sólo como capaces de argumentar, de seguir unas reglas lógicas, sino también como seres capaces de comunicarse, de sintonizar...de ahí la necesidad de tener en cuenta en el diálogo formas de comunicación distintas de la argumentación, expresivas de formas de vida únicas, vividas a lo largo de la historia, sometidas a las presiones de la vida cotidiana, aunque la argumentación sea la que decide en última instancia si las normas son justas.

(Cortina, 2009: 2006)

Este tipo de ampliación de las posibilidades de argumentación permite complementar los paradigmas descriptivos y procedimentales que han tenido hasta ahora preeminencia a la hora de pensar e interpretar la política. También es posible penetrar en el significado y en el sentido de la democracia desde lenguajes que permiten vincular los argumentos de la razón con los argumentos de la vida, por medio de la retórica entendida como una exploración creativa por el ethos el pathos y el logos de la convivencia ciudadana. 


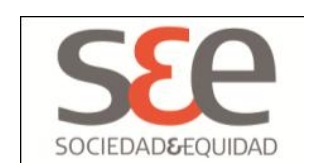

\section{Referencias Bibliográficas}

Annan, Koffi (1997) Discurso pronunciado por el Secretario General de la ONU, el 10 de diciembre de 1997 en la Universidad de Teherán, con motivo del cincuentenario de la Declaración Universal de Derechos Humanos. Nueva York: Naciones Unidas. Disponible desde Internet en formato PDF en <http://www.un.org/spanish/hr/50/dpi1937g.htm>

Aristóteles, (1990) Retórica Madrid: Gredos.

Augé, Marc (1998) La guerra de los sueños. Barcelona: Gedisa.

Cortina, Adela (2009) Ética de la razón cordial. Oviedo: Nobel.

Cortina, Adela (2010) Las claves de la democracia deliberativa. I Congreso Internacional de Bioética: bioética, reconocimiento y democracia deliberativa, Universidad de Valencia. [texto no publicado].

Crouch, Colin (2004) Posdemocracia. Madrid: Taurus.

Dahl, Robert (1992) La democracia y sus críticos. Barcelona: Paidós.

De Sousa Santos, Boaventura (2004) Democratizar la democracia: los caminos de la democracia participativa, México: FCE.

Dworkin, Ronald (2003) Virtud soberana, la teoría y la práctica de la igualdad. Barcelona: Paidós.

Feenstra, Ramón (2010) Sociedad Civil: Democracia monitorizada y medios de comunicación en John Keane. Castellón: Tesis de Doctorado. Departamento de Filosofía y Sociología. Universitat Jaume I.

Corporación Latinobarómetro (2010) Informe 2010. Santiago de Chile. Disponible desde Internet en formato PDF en

<http://www.latinobarometro.org/docs/INFORME_LATINOBAROMETRO_2010.pdf >

López Aranguren, José Luis (2011) Ética y política. Voces críticas. Madrid: Público.

Mandelbaum, M. (2008) Las raíces de la democracia moderna. En Los mercados y la democracia. Washington: Ejournal USA, volumen 13, № 6. Departamento de Estado de Estados Unidos.

Mouffe, Chantal (2003) La paradoja democrática. Barcelona: Gedisa.

Habermas, Jürgen (2008) Facticidad y validez. Madrid: Trotta.

Hagopian, Frances (2006) Democratización: avances y retrocesos en América Latina. Revista Ciencia Política. Volumen 26, pp 231- 239. Santiago de Chile. 


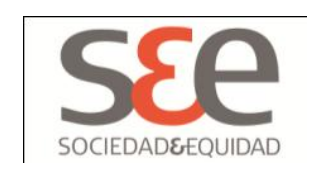

Huntington, Samuel (1994) La tercera ola. La democratización a finales del siglo XX. Barcelona: Paidós.

Organización de los Estados Americanos [OEA] (2001) Carta democrática interamericana Washington: Unidad para la Promoción de la Democracia (UPD).

Programa de las Naciones Unidas para el Desarrollo [PNUD] (2010) .Actuar sobre el futuro. Romper la transmisión intergeneracional de la desigualdad. Informe regional sobre desarrollo humano para América Latina y el Caribe. Disponible desde Internet en formato PDF en < www.idhalc-actuarsobreelfuturo.org/.../informe.php >

Keane, John (2009) The life and death of democracy. London: Simon \& Schuster.

Kelsen, Hans (2006) De la esencia y valor de la democracia. Oviedo: KRK ediciones.

Ricoeur, Paul (1977) La Metáfora viva. Buenos Aires: Megápolis / La Aurora.

Rosanvallon, Pierre (2007) La contrademocracia. Buenos Aires: Manantial

Rosemberg, Arthur (2006) Democracia y lucha de clases en la Antigüedad (1921). Mataró: El Viejo Topo.

Ruiz Soroa, J. M. (2009) El pueblo contra la Constitución. Madrid: El País [06 Enero 2009].

Schumpeter, Joseph (1985) Capitalism, Socialism and Democracy. New York: Harper and Bothers.

Sartori, Giovanni (2003) ¿Qué es la democracia?. Madrid: Taurus.

Sen, Amartya (2006) La démocratie des autres. Paris: Rivage Poche Petite Bibliotèque.

Spivak, Gayatri (2003) ¿Puede hablar el subalterno?. Revista Colombiana de Antropología, № 39, 2003: 297-364.

Zavaleta, René (2009) La autodeterminación de las masas. Bogotá: Siglo del hombre-CLACSO

Squella, A. (1984) Idea de la democracia en Kelsen. Estudios Públicos: № 13, 47: 60.

TNS CSOP (2010) Atitudini şi opinii despre regimul comunist din România Sondaj de opinie publică. Bucuresti: Institutul de Investigare a Crimelor Comunismului în România (IICCR) Disponible desde Internet en formato PDF: <http://www.csop.ro/fck_fisiere/file/Atitudini\%20si\%20opinii\%20despre\%20regimul\%20comunist \%20din\%20Romania.pdf>

Žižek, Slavoj (2011) Why fear the Arab revolutionary spirit?. Disponible desde Internet en formato HTML: <http://www.guardian.co.uk/commentisfree/2011/feb/01/egypt-tunisia-revolt> 